\title{
Adoption of Just-in-time Manufacturing By Rural and Urban Plants
}

\author{
H. Frederick Gale, Jr.*
}

\begin{abstract}
This study investigates the effect of rural location and access to other firms on adoption of just-in-time (JIT) and access to JIT-using customers in a sample of plants representing all manufacturing industries. Nonmetropolitan location, proximity to other firms, and interstate highway access do not appear to be important determinants of JIT involvement. Plants in the East North Central and Mountain regions are more likely than those in the Pacific region to be involved in JIT, when other characteristics are held constant. A number of plant characteristics, including plant size, ownership, age, workforce education, and use of marketing assistance, have significant effects on JIT involvement. However, the statistical models appear to have relatively little explanatory power, suggesting that JIT involvement is largely determined by factors not measured by the model.
\end{abstract}

\section{INTRODUCTION}

Just-in-time (JIT) inventory management is part of an approach to manufacturing and distribution that aims to increase efficiency, improve quality control, reduce inventory costs, and permit firms to respond rapidly to changes in demand by accommodating shorter, customized production runs (Germain and Dröge 1998; Linge 1991; Nassimbeni 1995). Supplies and components are delivered from the supplier to the manufacturer in small lots on a continuous basis, sometimes as frequently as several times per day. Initially introduced to the United States by Japanese-owned auto manufacturers, JIT was adopted by auto and electronics manufacturers during the 1980s and it was quickly adopted in other sectors. JIT is a core practice of the "flexible" or "lean" manufacturing model that is gradually displacing assembly line modes of mass production that have prevailed through most of the twentieth century (Testa 1993; Klier 1995).

This article examines spatial patterns of JIT adoption using a 1996 survey of manufacturing establishments. There are several reasons for studying adoption of JIT. First, although JIT is an important new innovation, little is known about the extent of its use and its diffusion across firms. Previous studies of JIT have been limited in scope to Japanese transplants, auto manufacturers, and the electronics industry (Reid 1995; McCann and Fingleton 1996). This study is the first to look at JIT use across all manufacturing industries. Little and Triest (1996) emphasize the importance of understanding the geography of technology adoption. Knowledge spillovers and diffusion of new innovations among firms in densely populated urban areas play an important role in theories that attempt to explain the geographic concentration of economic activity, yet there has been little empirical

*Economist, Food and Rural Economics Division, Economic Research Service, U.S. Department of Agriculture. 
study of the spatial diffusion process. Study of JIT adoption can provide information about the spatial diffusion of a relatively new and important innovation.

Studying geographic patterns of JIT adoption is also important because there is much uncertainty in the literature about the spatial effects of JIT on industrial location. A number of authors have suggested that JIT's emphasis on quick and frequent deliveries, closer relationships among firms, and communication could strengthen the importance of geographic proximity among firms, providing an additional agglomerative force that could lead to greater concentration of economic activity. In particular, Bernat (1994) and Testa (1993) raised concerns about the implications of JIT for the rural economy and for industrial development strategies. The perceived importance of geographic proximity among firms has popularized the development of localized industry clusters as a development strategy, and JIT is believed to reinforce the importance of clustering (Barkley and Henry 1997). However, the importance of geographic proximity to JIT is not settled. In the United States, cheap, reliable transportation, advanced communications, and the emergence of freight-forwarding firms reduce the importance of physical distance as a barrier. Further, rural locations offer other advantages (e.g., inexpensive nonunion labor, greenfield sites) that are attractive to JIT users. Thus, the spatial implications of JIT are potentially important, but the effect is a priori ambiguous and becomes an empirical question. Study of the geographic patterns of JIT use can provide some initial answers.

This study investigates whether rural manufacturers are less likely than their urban counterparts to use JIT or to supply a customer using JIT. Effects of several measures of rurality and proximity to other firms on adoption of JIT are estimated, holding plant characteristics constant. While there has been considerable discussion about the likely patterns of JIT use with respect to rural location and industrial clustering, this is the first study that has compared JIT use by rural and urban manufacturers. Many previous studies of JIT focused on a particular industry, often auto manufacturing or electronics. However, this study looks at JIT use in a sample of establishments from all major manufacturing industries. Most surveys of manufacturers have few rural firms, but the survey employed in this study includes a large sample of rural establishments.

\section{JUST-IN-TIME AND PROXIMITY AMONG FIRMS}

Adoption of JIT occurs if (1) the establishment learns about the innovation; and (2) the benefits of adopting JIT exceed the costs. Proximity to other firms (in an urban area or cluster of firms) may increase the likelihood that an establishment adopts JIT by speeding diffusion of information about the innovation. Additionally, adoption of JIT may be more profitable for firms located in close proximity to suppliers and customers. Proximity to other firms may facilitate communication between customers and suppliers and the fast response to orders necessary for successful implementation of JIT.

Economists have long been interested in the diffusion of innovations. Theories of agglomeration economies suggest that innovations tend to be developed 
and initially adopted in densely populated urban centers where interaction among firms enhances exchange of information and ideas, later spreading to hinterlands (e.g., Glaeser et al. 1992; Moomaw 1983). Geographic proximity among firms hastens the spread of innovations by increasing the number and frequency of contacts among firms. Access to localized pools of skilled labor and services also may promote the spread of innovations among an agglomeration of firms. There is some evidence of a contagion effect (firms located near adopters are more likely to adopt) in diffusion of innovations (Rees, Briggs, and Oakey 1984; Little and Triest 1996), but there is relatively little evidence of spatial diffusion that favors cities or other agglomerations. Two studies of metalworking and machinery manufacturing industries (Little and Triest 1996; Gale 1998) found essentially no rural-urban gap in adoption of advanced technology. Harrison, Kelley, and Gant (1996) found that adoption of programmable automation among metalworking firms was highest in small cities as compared with rural and urban areas, but they found no association with clustering of similar firms. Gale (1997) found a modest rural-urban gap in advanced technology use that could be explained by differing industry mix. Many of the technologies examined in those studies were relatively mature, and may have had time to diffuse to rural areas. Wojan (1998) studied the adoption of a newer practice, ISO 9000 quality certification, using a sample of southern manufacturers. Wojan (1998) found that adoption in some rural areas is comparable to urban rates, while other rural areas had no adopters. Kusmin (1996) found a significantly lower rate of computer use among rural workers.

Even if there is no spatial diffusion effect, there are strong reasons to expect an association between JIT adoption and proximity of firms. McCann and Fingleton (1996) and Nassimbeni (1995) cite authors who suggest that JIT's demands for more frequent deliveries, short lead times, closer ties between producers and suppliers, and exchange of design and engineering information imply a greater need for geographic proximity between JIT-using firms and their suppliers. Germain and Dröge (1998) note that much research on JIT implementation has focused on communication and other relations between customers and suppliers. Smith and Florida (1994) argue that the tightly linked JIT purchasing structure promotes interdependence among the industrial location decisions of suppliers and end users. Reid (1995, pp. 346-47) and Linge (1991, pp. 325-26) cite a number of authors who suggest that geographic proximity is important to facilitate JIT. Besides the advantages of quick delivery times, Reid (1995) cites a number of authors who have argued that face-to-face communication made possible by spatial clustering of suppliers and customer firms is also a key to successful use of JIT. McCann and Fingleton (1996) modified the familiar Economic Order Quantity model to show that reducing the average distance of input deliveries (i.e., more local sourcing of inputs) is one means of reducing the size of input shipments (to accommodate JIT) without increasing total ordering costs. They conclude that JIT could result in more local sourcing. In their empirical work, McCann and Fingleton (1996) and Reid (1995) found that JIT encouraged plants to 
purchase materials and parts locally, thus encouraging the development of strong local linkages and spatial clustering by members of a JIT network.

Distance to suppliers could also increase the risk of disruptions in the flow of inputs, which may be more costly under JIT than under more traditional assembly line methods. JIT manufacturers maintain small inventories of parts and supplies (relying on a constant flow of deliveries), thus a delayed, flawed, or otherwise unsatisfactory shipment is more likely to cause costly disruptions of the production process. Smaller distance to suppliers should also reduce the risk of disruptions in the flow of inputs, thus reducing the expected costs of such disruptions if JIT is adopted. The likelihood that an establishment at a given location adopts JIT will rise as the average distance to suppliers falls (as the concentration of nearby firms increases). By similar reasoning, an establishment's likelihood of supplying a JIT-using customer can be expected to rise, the shorter the distance to potential customers. The larger the number of JIT-using establishments nearby, the greater the likelihood of identifying a JIT-using potential customer. If distance is a barrier to JIT implementation, the likelihood of being chosen as a supplier to a JIT-using customer will rise, the shorter the average distance to potential customers (the greater the concentration of nearby firms).

While there seem to be reasons to expect an association between JIT use and proximity, most authors conclude that there is no clear consensus about the agglomerative impacts of JIT. Relatively low transportation costs and good communication networks in the United States reduce the cost and uncertainty associated with long-distance shipments (Appold 1995). Specialist freighthandling firms have facilitated the geographic separation of assembly plants and subcontractors (Linge 1991). Authors agree that geographic concentration of manufacturers in Japan (where the JIT concept originated) may be an unusual case, perhaps due to poor transportation infrastructure in Japan. In the United States, Klier (1995) found that more recently established suppliers to auto manufacturers were more spatially concentrated than older establishments, but they were still widely scattered over five or more states (a region that includes many rural areas). Mair, Florida, and Kenney (1988) conclude that concentration of Japanese-owned auto manufacturers established in the United States is at the state or region level, not necessarily at the local level. Nassimbeni's (1995) study of Italian manufacturers did not find an association between JIT implementation and closeness of suppliers. Glasmeier and McCluskey (1987) suggested that JIT supply systems can be successfully negotiated over distances of 650 kilometers or more. Appold (1995) examined distances between customers and suppliers in the U.S. metalworking industry and found no evidence that location in an agglomeration of firms increases establishment performance. The advantages of rural locations (low-cost land and labor, greenfield sites, less resistance to new practices outside the urban manufacturing belt) may offset the disadvantage of distance to suppliers for JIT users. Authors have also noted that Japanese transplants have shown a preference for less urbanized southern locations outside the traditional U.S. manufacturing belt. 
Thus, the effect of JIT on spatial concentration of industry is an empirical question. Given the importance of JIT as a core practice in "flexible" or "lean" manufacturing and its potential to alter the economic landscape, empirical evidence about the spatial pattern of JIT use is needed. While anecdotal evidence of spatial shifts in manufacturing associated with JIT has been offered, there has been little study of the spatial aspect of JIT. JIT's increasing prevalence has important implications for industrial development. If JIT demands geographic proximity to other firms, rural locations will be at a disadvantage in industrial recruitment and retention of existing businesses. Studying the adoption of JIT is also interesting as a study of the spatial diffusion of an important management innovation.

\section{DATA AND METHODOLOGY}

This study examines the likelihood that an establishment has adopted JIT and/or supplies a JIT-using customer at a given point in time. In particular, the study addresses the question of whether JIT involvement is equally likely for firms at rural and urban locations. Urbanization, per se, is not the variable that affects JIT use. Rather, it is proximity to other firms that should affect JIT involvement. Proximity is usually, but not always, associated with urbanization.

This study employs data from the 1996 Rural Manufacturing Survey (RMS), conducted by the U.S. Department of Agriculture's Economic Research Service and Washington State University (Gale et al. 1999). The RMS is a nationwide survey of manufacturing establishments intended to provide information about barriers to competitiveness faced by rural businesses. Respondents were asked about a wide range of issues, including their use of production and communications technologies, use of management practices, problems they face, characteristics of their workforces, and methods of financing. These data provide a rare glimpse of the extent to which flexible manufacturing practices are being used by manufacturers of various characteristics in rural and urban locations.

The goal of the survey was to obtain reliable information on nonmetro establishments as well as a small sample of metro establishments for comparison. A stratified sample of manufacturing establishments with at least 10 employees was chosen from a list provided by a private vendor. Stratification of the RMS sample was based on metro-nonmetro location, nonmetro west-nonwest, and three employment size classes. The data were collected in a half-hour phone interview with the most senior manager available at the location. ${ }^{1}$ The response rate was 68 percent. Responses were obtained from about 2,800 nonmetro manufacturing plants and 1,100 metro plants. Sample weights were developed for use in statistical analysis such that weighted establishment numbers reflect the actual number of establishments reported in the U.S. Bureau of the Census, County

\footnotetext{
${ }^{1}$ The interviewer asked who, at that location, was most knowledgeable about the broad range of issues addressed in the questionnaire. About two-thirds of target respondents were either a head of the organization or the general/plant manager. In branch plants, more than half of the target respondents were heads of production, while in headquarters establishments the largest number of respondents were heads of the organization. Human resources directors and financial and administrative officers responded in a significant number of establishments.
} 
Business Patterns, 1994.2 All statistics reported in this study were obtained using sample weights. The relatively large number of rural plants in this survey (most surveys have few observations) makes it possible to make meaningful ruralurban comparisons.

The measures of JIT used in this study are discrete measures based on two yes/no questions:

1. "Do you use a just-in-time inventory and production system?"

2. "Do you act as a supplier to any other establishments (including other establishments within this firm) that use a just-in-time inventory and production system?"

A measure of the extent or intensity of JIT use would be preferred. For example, Reid (1995) measured JIT use by "the proportion of the value of a plant's material inputs which are delivered JIT." Unfortunately, the survey used in this study cannot distinguish between a plant that has one or two JIT-using customers out of fifty and one that sells primarily to JIT-using customers. Nor can it distinguish between a plant that may be experimenting with JIT on a small scale and one that is fully committed to JIT.

The hypothesis that involvement in JIT as a user or supplier increases with proximity to firms is tested by estimating multivariate probit models. This permits testing for proximity effects while holding other establishment characteristics constant, such as plant size and ownership, industry, and workforce characteristics. Two discrete endogenous variables were defined based on the information available in the data employed for this study. For establishment $\mathrm{i}$ at location $\mathrm{k}$, JITUSE $_{\mathrm{ik}}=1$ if the establishment uses JIT, 0 otherwise, and JITCUS ${ }_{\mathrm{ik}}=1$ if the establishment has a JIT-using customer, 0 otherwise. It seems likely that the probability of JIT adoption and the probability of having a JIT customer are interdependent. Additionally, JITUSE $_{\mathrm{ik}}$ and JITCUS $\mathrm{ik}_{\mathrm{ik}}$ are hypothesized to depend on characteristics of their location, $\mathrm{L}_{\mathrm{k}}$, which affect proximity to other firms, and a vector of establishment characteristics $\left(X_{1 \mathrm{i}}\right.$ and $\left.\mathrm{X}_{2 \mathrm{i}}\right)$. The two-equation system is:

$$
\begin{aligned}
& \operatorname{Pr}\left(\text { JITUSE }_{\text {ik }}=1\right)=f\left(L_{k}, X_{1 \mathrm{i}}, e_{1 \mathrm{i}}\right) \\
& \operatorname{Pr}\left(\text { JITCUS }_{\text {ik }}=1\right)=f\left(L_{k}, X_{2 \mathrm{i}}, e_{2 \mathrm{i}}\right),
\end{aligned}
$$

where $f()$ is a function based on the standard normal density function and $e_{1 i}$ and $\mathrm{e}_{2 \mathrm{i}}$ are stochastic error terms with mean 0 and variance 1 . It is likely that the two error terms will be positively correlated $\left(\operatorname{cov}\left(e_{1 i}, e_{2 i}\right)=\rho>0\right)$ since factors not captured by the model that have an effect on JITUSE would have a similar effect on JITCUS. Estimates were obtained by full information maximum likelihood using LIMDEP econometric software (Greene 1995). ${ }^{3}$

Several locational measures of proximity and access to other firms were developed by identifying the county in which the establishment was located.

${ }^{2}$ The 1994 edition was the most recent edition of County Business Patterns available at the time weights were developed. The 1996 edition of County Business Patterns reported that there were 190,000 manufacturing establishments with 10 or more employees.

${ }^{3}$ In preliminary analysis, JITUSE and JITCUS were included as endogenous right-hand-side variables, but they were dropped due to nonsignificance. 
First, NONMET is a general measure of the degree of urbanization. NONMET $=1$ if the establishment's county is located outside a metropolitan area, 0 if it is located in a metro area. This measure is used for two reasons. Urbanization is usually (though not always) associated with greater proximity to other firms, so NONMET can be used as a proxy for (lack of) proximity to other firms. Second, NONMET is a convenient measure that is easily understood by policy and economic development officials. This study is concerned with the implications of JIT for the rural economy, which is often defined as nonmetropolitan counties. If JIT use is less likely in rural areas, NONMET will have a negative association with JIT use.

ESTABS is the number of manufacturing establishments in the establishment's multicounty Bureau of Economic Analysis (BEA) area reported in 1994 County Business Patterns published by the U.S. Bureau of the Census. ESTABS is a measure of proximity to manufacturing suppliers and customers. ESTABS is included to capture the possible effect on JIT involvement of being located in a place where manufacturing activity is concentrated. The BEA area was used as the geographic unit for ESTABS rather than the county because BEA areas are fairly large and they are defined on the basis of economic linkages. Given relatively good transportation and communications in the United States, it is common for customer-supplier relationships to extend beyond county boundaries. ${ }^{4}$

Highway access may be an important factor that improves access to potential customers and suppliers. According to Smith and Florida (1994), transportation plays a significant role in use of JIT in Japan, and they found that interstate highway access was associated with location choices by Japanese transplants in the U.S. Klier (1995) also found an association between the location of automotive manufacturers and interstate highways. This study includes INTMI, interstate highway mileage in the establishment's county in 1997 (as reported by the U.S. Department of Transportation) as a measure of highway access. INTMI could have a positive effect on JIT involvement if location near an interstate highway improves access to suppliers and customers enough to facilitate adoption of JIT or obtain JIT-using customers.

A set of regional dummy variables was included in the models to capture possible regional effects. For example, a firm located in the highly industrialized Midwest may be more likely to be involved in JIT than a firm located in the more sparsely populated Rocky Mountain region. The study used six regions that are based on combinations of the nine census divisions. The Census Bureau's South region extends from Maryland and Delaware to Texas and Oklahoma. A Northeast region was formed by combining the census New England and Mid-Atlantic divisions. The remaining four regions used in this study were the heavily industrialized East North Central, the more sparsely populated West North Central and Mountain divisions, and the Pacific division.

Establishment characteristics include size, type and ownership of the establishment and workforce characteristics. EMP, the average number of employees at the establishment during 1995, is a measure of plant size. Larger plants are ${ }^{4}$ In preliminary analysis, ESTABS at the county level was also employed, and the results were very similar to the results reported below. 
usually more likely to adopt new innovations like JIT. However, they also may have a larger, more far-flung supplier base, which could work against adoption of JIT. Thus, the a priori effect of plant size on JIT use is ambiguous. Larger plants tend to have a larger number of customers, which may increase the likelihood of having a JIT-using customer. Thus, plant size may have a positive effect on JITCUS. BRANCH and $\mathrm{HQ}$ are indicators of the ownership and type of plant, and may be a proxy for firm size. If both of these variables are zero, the plant is a single-unit establishment. Branch or headquarters plants of a multiunit firm are usually more likely to adopt innovations than single-unit establishments and may have better access to sophisticated JIT-using customers. Thus, BRANCH and HQ may have a positive effect on JITUSE and JITCUS. JIT is generally associated with production in small batches, while traditional assembly line operations are associated with large batch methods. Survey respondents were asked to choose one of four methods that best described their production process: large batch, small batch, custom, and other method. LGBATCH=1 if the respondent reported large batch methods, 0 otherwise. LGBATCH is expected to have a negative association with JITUSE and JITCUS. RND=1 if the establishment has a research and development unit. RND is an indicator of the technological sophistication of the establishment and is expected to have a positive effect on JITUSE and JITCUS. NEW=1 if the establishment was operating in 1996 but had not been operating in 1991. New establishments are more likely to adopt innovations, thus NEW is expected to have a positive effect on JITUSE and JITCUS. UNION=1 if the establishment is covered by a collective bargaining agreement, 0 otherwise. Unions have been characterized as opposing many new management innovations, so it is interesting to test whether unionization is negatively associated with JITUSE. MKTASST $=1$ if the establishment uses marketing assistance from outside the establishment, 0 otherwise. MKTASST is expected to have a positive effect on JITCUS, since marketing assistance may increase the likelihood of finding a customer that uses JIT. Marketing assistance is not expected to have a direct effect on adoption of JIT within the establishment, so MKTASST is excluded from the JITUSE equation. HS is the percentage of the establishment's production workers who completed high school. HS is included to test whether a more educated workforce is associated with greater likelihood of JIT adoption. Previous studies have found that firms with more educated workforces are more likely to adopt innovations. HS is excluded from the JITCUS equation. Finally, the models also include a set of 18 dummy variables that identify the establishment's industry. One dummy variable corresponds to each two-digit SIC code except for food (SIC 20) and tobacco (SIC 21), excluded to prevent collinearity.

\section{DESCRIPTIVE STATISTICS}

Overall, 48.1 percent of manufacturing plants reported using JIT in 1996 and 48.9 percent said they had a customer that used JIT (Table 1). ${ }^{5}$ About 30 percent of establishments both used JIT in their plant and supplied a customer that used

${ }^{5}$ The standard error for these estimates is 1.47 percentage points. 
JIT. This indicates that a large portion of the manufacturing sector is linked together by JIT relationships. About one-third of establishments had no connection to JIT: they neither used JIT in their own establishment nor supplied a customer that used JIT. The remaining third of establishments were equally split among those who used JIT but did not supply a JIT-using customer, and those who did not use JIT but did supply a JIT-using customer. JIT users were more likely to supply JIT customers than were nonusers: 64.6 percent versus 36.7 percent, suggesting that JITCUS and JITUSE are not independent.

TABLE 1

Percent of Establishments Using JIT and Supplying JIT Customers, 1996

\begin{tabular}{lccc}
\hline & \multicolumn{3}{c}{ Acts as a supplier to an establishment that uses JIT } \\
& YES & NO & ALL \\
\hline Uses JIT & 30.4 & 17.7 & 48.1 \\
Does not use JIT & 18.5 & 33.4 & 51.9 \\
All & 48.9 & 51.1 & 100.0 \\
\hline
\end{tabular}

Source: USDA, Economic Research Service, Rural Manufacturing Survey, 1996.

Figure 1 shows the geographic concentration of JIT-using establishments across multicounty BEA economic areas. Weighted counts of JIT users based on the RMS sample were generated for each BEA area. ${ }^{6}$ JIT users tend to be concentrated in the Midwest, but each region of the contiguous United States contained at least one BEA area with a large number of JIT users. Notable concentrations occur on the eastern seaboard from Philadelphia to Boston, the west coast from Seattle to Phoenix, the Great Lakes region, Minneapolis, Dallas-Fort Worth and Houston, Salt Lake City-Ogden and Denver-Boulder, Atlanta, Charlotte, and Orlando.

\section{FIGURE 1}

Number of JIT-Using Establishments, by BEA Economic Area, 1996

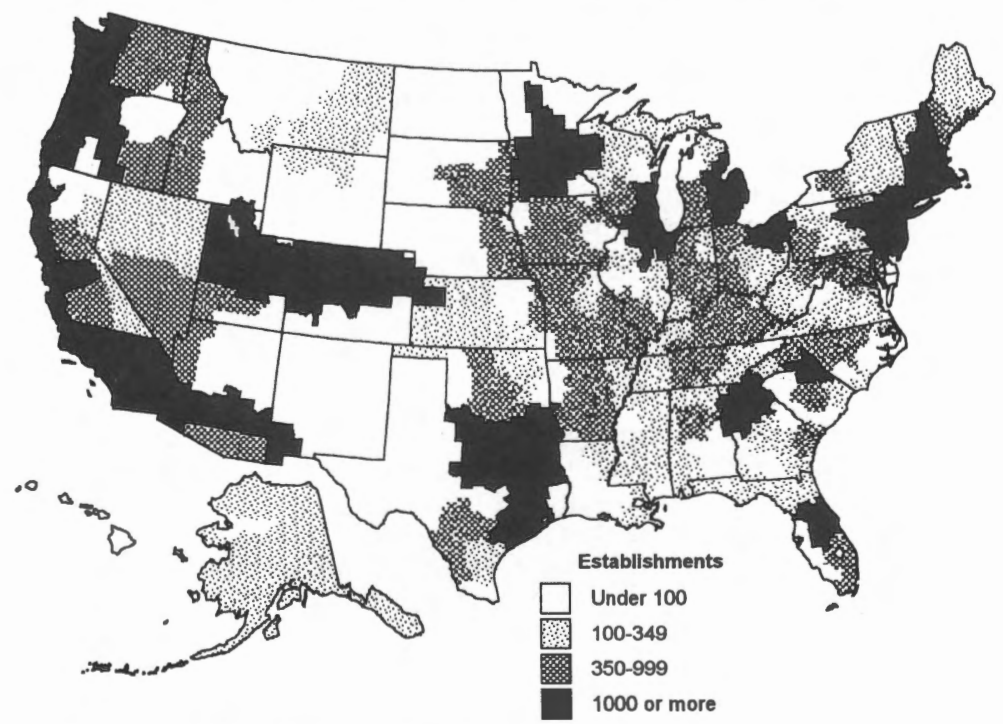

Source: Weighted counts from 1996 Rural Manufacturing Survey.

${ }^{6}$ Survey weights were developed by the Economic Research Service so that a weighted count of survey respondents would sum to the number of U.S. manufacturing establishments with 10 or more employees in 1994 (Gale et al. 1999). 
The variable means by JITUSE shown in Table 2 do not indicate that JIT users were more urbanized than nonusers in 1996. (Note that a comparison of means based on the value of JITCUS is very similar since JITUSE and JITCUS are correlated). Measures of proximity and access to other firms do not indicate that JIT users were concentrated in large agglomerations of manufacturing activity. About 20 percent of both JIT users and nonusers were located in nonmetro counties. Between 8 and 9 percent of both groups were in nonmetro counties not adjacent to a metro area. JIT nonusers were located in BEA areas that had an average of 3,053 manufacturing establishments, higher than the 2,669 for JIT users. Average interstate mileage was only slightly higher for JIT users (22.2 miles per county for JIT users, versus 21.1 miles for nonusers). The statistics do indicate that JIT users were relatively concentrated in the heavily industrialized East North Central region, but the difference is slight. The East North Central region has 24.6 percent of JIT users, but only 21.4 percent of nonusers. However, the sparsely populated Mountain and West North Central regions (where the importance of proximity to other firms would suggest that JIT would be more difficult to implement) appear to have their "fair share" of JIT users. There was no difference between the share of JIT users and nonusers in those regions.

TABLE 2

Proximity and Urbanization Measures

\begin{tabular}{|c|c|c|c|}
\hline \multirow[b]{2}{*}{ Variable } & \multirow[b]{2}{*}{ Description } & \multicolumn{2}{|c|}{$\begin{array}{l}\text { Weighted Mean' } \\
\text { JITUSE }=\end{array}$} \\
\hline & & 0 & 1 \\
\hline JITCUS & $=1$ if establishment has a customer that uses JIT, 0 otherwise & 0.367 & 0.646 \\
\hline NONMET & $=1$ if establishment's county is nonmetro, 0 if metro & 0.201 & 0.209 \\
\hline NONADI & $\begin{array}{l}=1 \text { if establishment's county is nonmetro and not adjacent to } \\
\text { a metro area, } 0 \text { otherwise }\end{array}$ & 0.083 & 0.088 \\
\hline ESTABS & $\begin{array}{l}\text { Number of manufacturing establishments in BEA area } \\
\text { (Source: County Business Patterns) }\end{array}$ & 3053 & 2669 \\
\hline INTMI & $\begin{array}{l}\text { Miles of interstate highway in establishment's county } \\
\text { (source: U.S. Department of Transportation) }\end{array}$ & 21.1 & 22.2 \\
\hline$\underline{\text { Regions }}$ & & & \\
\hline NE & ME, MA, VT, NH, RI, CT, NY, NJ, PA & 0.151 & 0.131 \\
\hline ENC & $\mathrm{OH}, \mathrm{IN}, \mathrm{IL}, \mathrm{MI}, \mathrm{WI}$ & 0.214 & 0.246 \\
\hline WNC & MN, IA, MO, ND, SD, NE, KS & 0.025 & 0.024 \\
\hline SOUTH & $\begin{array}{l}\text { MD, DE, VA, WV, NC, SC, TN, GA, FL, KY, AL, MS, AR, } \\
\text { LA, TX, OK }\end{array}$ & 0.223 & 0.223 \\
\hline MOUNTAIN & CO, UT, WY, NV, MT, ID, NM, AZ & 0.093 & 0.104 \\
\hline PACIFIC & CA, OR, WA, AK, HI & 0.293 & 0.272 \\
\hline EMP & Establishment total employment & 70.3 & 124.6 \\
\hline BRANCH & $=1$ if branch plant of a multiunit firm, 0 otherwise & 0.166 & 0.234 \\
\hline HQ & $=1$ if headquarters of a multiunit firm, 0 otherwise & 0.150 & 0.165 \\
\hline LGBATCH & $=1$ if large batch production methods used, 0 otherwise & 0.243 & 0.269 \\
\hline RND & $=1$ if establishment has research and development unit, 0 otherwise & 0.275 & 0.279 \\
\hline NEW & $=1$ if newly established since 1992,0 otherwise & 0.023 & 0.047 \\
\hline UNION & $=1$ if covered by collective bargaining agreement, 0 otherwise & 0.146 & 0.149 \\
\hline MKTASST & $=1$ if uses outside marketing assistance, 0 otherwise & 0.355 & 0.399 \\
\hline HS & Percent of production workers who completed high school & 77.5 & 80.8 \\
\hline & Unweighted number of observations & 1661 & 1769 \\
\hline
\end{tabular}

${ }^{*}$ Weighted to reflect the U.S. population of all manufacturing establishments with 10 or more employees. Source: USDA, Economic Research Service, Rural Manufacturing Survey, 1996, except where noted.

${ }^{7}$ The statistics were weighted to reflect the population of all manufacturing establishments with 10 or more employees. The unweighted percentage of nonmetro establishments in the sample was about 70 percent. 
A few plant characteristics were quite different for users and nonusers. JIT users had more employees, were more likely to be branch or headquarters plants, more likely to have a research and development unit, more likely to use marketing assistance, and had a higher percentage of high school graduates in their workforce than did nonusers. Surprisingly, JIT users were also more likely than nonusers to use large batch production methods, contrary to expectations.

Table 3 shows the rate of JIT use and the percentage of establishments with JIT customers by a more detailed measure of urbanization of the establishment's county. The 10 categories of the USDA/ERS Beale code (Butler 1994) were collapsed into six, based on the size of the county's metro area, the size of the urbanized population in nonmetro counties, and whether the nonmetro county was adjacent to a metro county. If proximity to other firms is an important factor in JIT adoption, we would expect a higher percentage of JIT users in metro counties as compared with nonmetro counties. We would also expect a higher percentage of JIT users in nonmetro counties with a larger urban population, and in metroadjacent as compared with nonadjacent nonmetro counties. However, the JITUSE and JITCUS rates do not vary much by degree of urbanization. Average JITUSE and JITCUS rates in Table 3 fall in a narrow range, and chi-square tests fail to reject the hypothesis that JIT involvement rates (JITUSE and JITCUS) are equal across urbanization categories. Thus, the adoption rates by urbanization do not indicate a rural-urban difference in JIT adoption rates.

TABLE 3

Establishments Using JIT, by Urbanization, 1996

\begin{tabular}{llccc}
\hline Type of county & Definition & $\begin{array}{c}\text { Unweighted } \\
\text { sample size } \\
\text { (number) }\end{array}$ & $\begin{array}{c}\text { JITUSE* } \\
\text { users (\%) }\end{array}$ & $\begin{array}{c}\text { JITCUS* } \\
\text { suppliers (\%) }\end{array}$ \\
\hline $\begin{array}{l}\text { Large metro } \\
\text { Other metro }\end{array}$ & $\begin{array}{l}\text { MSA population } \\
\text { 1 million or more }\end{array}$ & 675 & 47.9 & 48.7 \\
$\quad$ Under 1 million & 361 & 48.1 & 48.0 \\
$\begin{array}{l}\text { Nonmetro } \\
\quad \text { Adjacent to metro area }\end{array} \quad$ Urban pop. >20,000 & 630 & 48.6 & 49.4 \\
$\quad$ Urbanized & Urban pop. <20,000 & 968 & 47.1 & 48.2 \\
$\quad \begin{array}{l}\text { Not Adjacent to metro area } \\
\quad \text { Urbanized } \\
\quad \text { Less-urbanized }\end{array}$ & Urban pop. >20,000 & 306 & 51.1 & 53.5 \\
$\quad$ Urban pop. <20,000 & 866 & 47.7 & 47.2 \\
Chi-square & & & 2.2 & 1.9 \\
\hline
\end{tabular}

*Weighted to reflect population of manufacturing establishments with 10 or more employees.

**Test statistic for hypothesis that means are equal across urbanization categories. Critical value $\chi^{2}(4) \alpha=.05=9.49$. Source: USDA, Economic Research Service, Rural Manufacturing Survey, 1996.

\section{RESULTS}

Bivariate probit estimates for JITCUS and JITUSE equations are presented in Table 4. Two sets of estimates are presented: one pair of equations for all observations and a second pair for nonmetro observations only. The first model allows a test of whether nonmetro establishments are less likely than urban 
establishments to use JIT or supply JIT customers. The nonmetro model indicates which variables are associated with greater JIT involvement among nonmetro establishments. Nearly three-fourths of the sample establishments are from nonmetro counties, reflecting the stratification of the sample. Probit estimates were computed with sample weights to more accurately reflect the population. The coefficients for 18 industry dummy variables are shown in an appendix table.

TABLE 4

JIT Probit Equations

\begin{tabular}{|c|c|c|c|c|c|c|c|c|}
\hline \multirow[b]{3}{*}{$\begin{array}{l}\text { NONMET } \\
\log (\text { ESTABS })\end{array}$} & \multicolumn{4}{|c|}{ All Observations } & \multicolumn{4}{|c|}{ Nonmetro Only } \\
\hline & \multicolumn{2}{|c|}{ JITUSE } & \multicolumn{2}{|c|}{ JITCUS } & \multicolumn{2}{|c|}{ JITUSE } & \multicolumn{2}{|c|}{ JITCUS } \\
\hline & $\begin{array}{l}0.034 \\
0.048^{*}\end{array}$ & $\begin{array}{l}(0.55) \\
(2.08)\end{array}$ & $\begin{array}{l}-0.003 \\
-0.003\end{array}$ & $\begin{array}{l}(0.06) \\
(0.16)\end{array}$ & -0.024 & $(-0.94)$ & -0.021 & $(-0.83)$ \\
\hline $\mathrm{NE}$ & -0.005 & $(-0.07)$ & 0.018 & $(0.23)$ & -0.138 & $(-0.97)$ & 0.015 & $(0.49)$ \\
\hline ENC & $0.151^{*}$ & $(2.18)$ & $0.305^{*}$ & (4.39) & 0.027 & $(0.21)$ & $0.129 *$ & (4.55) \\
\hline WNC & 0.066 & $(0.41)$ & 0.010 & $(0.06)$ & -0.154 & $(-0.95)$ & 0.020 & $(0.31)$ \\
\hline SOUTH & 0.094 & $(1.31)$ & -0.010 & $(-0.14)$ & 0.026 & $(0.20)$ & 0.008 & $(0.26)$ \\
\hline MOUNTAIN & 0.090 & $(0.98)$ & $0.187^{*}$ & $(2.05)$ & 0.028 & $(0.17)$ & $0.084^{*}$ & (2.40) \\
\hline INTMI & 0.0006 & $(1.02)$ & 0.0009 & (1.36) & 0.0009 & $(1.23)$ & 0.0007 & $(0.69)$ \\
\hline HQ & 0.018 & $(0.26)$ & $-0.495^{*}$ & $(-7.18)$ & -0.122 & $(-1.53)$ & $-0.218^{*}$ & $(-2.76)$ \\
\hline BRANCH & $0.207^{*}$ & (3.13) & $-0.350^{*}$ & $(-5.05)$ & $0.189^{*}$ & $(2.76)$ & $-0.145^{*}$ & $(-2.08)$ \\
\hline LOG(EMP) & $0.156^{*}$ & $(6.05)$ & $0.187^{*}$ & $(7.33)$ & $0.092^{*}$ & (3.36) & $0.095^{*}$ & (3.46) \\
\hline HS & $0.002^{*}$ & $(2.84)$ & & & -0.0015 & (1.33) & & \\
\hline MKTASST & & & $0.215^{*}$ & (4.35) & & & $0.173^{*}$ & (3.30) \\
\hline NEW & $0.446^{*}$ & (3.72) & $0.337^{*}$ & (2.46) & $0.310^{*}$ & (2.53) & 0.071 & $(0.58)$ \\
\hline RND & 0.001 & $(0.03)$ & $-0.175^{*}$ & $(-3.10)$ & 0.091 & (1.36) & -0.093 & $(-1.39)$ \\
\hline UNION & $-0.121+$ & $(-1.81)$ & -0.079 & $(-1.14)$ & $-0.138+$ & $(-1.75)$ & $-0.143+$ & $(-1.81)$ \\
\hline LGBATCH & -0.004 & $(-0.07)$ & 0.037 & $(0.70)$ & 0.047 & $(0.80)$ & 0.073 & (1.25) \\
\hline$\rho$ (t-value) & & 0.45 & (18.4) & & & 0.55 & (21.9) & \\
\hline McFadden R-square & & 0.06 & & & & 0.04 & & \\
\hline Chi-square (df) & & & & & & & & \\
\hline All variables $=0$ & & 561.0 & (68) & & & 286.9 & (66) & \\
\hline All location variables $=0$ & & 42.6 & (16) & & & 38.6 & (14) & \\
\hline $\begin{array}{l}\text { All location variables } \\
\text { except region dummies }=0\end{array}$ & & 4.4 & (6) & & & 3.7 & (4) & \\
\hline
\end{tabular}

Probit coefficients shown with t-ratios in parentheses. Estimated as a two-equation system with full information maximum likelihood using LIMDEP econometric software. Dummy variables corresponding to two-digit SIC industry codes were also included in the probit equations, but coefficients are not shown to conserve space.

* Significantly different from 0 at the $5 \%$ level.

+ Significant at the $10 \%$ level.

Coefficients significantly different from zero at the $5 \%$ level are marked with $a^{*}$. Those significant at the $10 \%$ level are marked with $a+$. There are a number of significant coefficients and the chi-square statistic rejects the hypothesis that all coefficients are equal to zero. However, the models appear to have low explanatory power based on the McFadden $\mathrm{R}^{2}$. The significant parameter indicates a positive correlation between the disturbances of the two equations. This suggests that there may be factors not captured in the models that influence both JITUSE and JITCUS. These are probably idiosyncratic internal characteristics of managers or firms that are difficult to measure with a survey instrument. Livingston and Eff (1999) drew a similar conclusion from the poor performance of 
their model in predicting export decisions of manufacturing establishments in the rural south.

Consistent with the descriptive statistics above, urbanization variables do not have much influence on JIT involvement. NONMET has no significant effect in either the JITUSE or JITCUS equation. The log of ESTABS has a positive effect on JITUSE, indicating that JIT use is more likely in regions that have a larger number of manufacturing establishments. The effect is rather weak, however. Increasing the value of ESTABS from 1,200 to 6,000 (from roughly the first to the third quartile), holding other variables constant at their means, increases the model's predicted probability of adopting JIT from 47 percent to 49 percent. ESTABS does not have a significant effect on JITCUS in the model for all observations. ESTABS is not significant in either of the equations for nonmetro establishments. ${ }^{8}$

Miles of interstate highway in the establishment's county does not have a significant effect in any of the equations. Thus, access to interstate highways does not appear to facilitate JIT involvement when other characteristics are held constant. ${ }^{9}$ However, this may not be an adequate measure of access to highways. For example, it is possible that an establishment located immediately adjacent to a highway is more likely to use JIT than another establishment in the same county that is 20 miles from a highway.

Of the regional dummy variables, only ENC is significantly different from zero in the JITUSE model. ENC and MOUNTAIN are significant in the JITCUS equation. The excluded region is the Pacific. Holding other factors constant, the probability of adopting JIT and the probability of supplying JIT customers are higher in the East North Central region as compared with the Pacific region. Supplying JIT customers is also more likely in the Mountain region as compared with the Pacific region. Setting other variables at their means, the model predicts that the probability of JIT adoption is 51 percent for an East North Central establishment versus 47 percent for a Pacific establishment. JIT use in other regions is not significantly different from the Pacific region. The hypothesis that the coefficients on NE, WNC, SOUTH, and MOUNTAIN are jointly equal to zero cannot be rejected. The coefficient on ENC is significantly different from zero when other coefficients are restricted to equal zero, indicating that JIT use in the East North Central region is more likely than in other regions. Supplying a JIT customer in the Mountain region is more likely than in the Pacific region, but not significantly different from the West North Central, South, and Northeast regions.

In the JITCUS model ENC and MOUNTAIN have significant positive coefficients. The hypothesis that coefficients on NE, WNC, and SOUTH are jointly zero cannot be rejected, while ENC and MOUNTAIN are both significant in that specification. Thus, JITCUS $=1$ is more likely in the East North Central and ${ }^{8}$ Models were also estimated with an ESTABS variable constructed on a county basis, that is, the number of manufacturing establishments per county. The results were nearly identical to those obtained with ESTABS constructed on the BEA-area basis. ESTABS was significant in the JITUSE equation, but not in the JITCUS equation for all observations. It was nonsignificant in the nonmetro equations.

${ }^{9}$ Preliminary work also included miles of noninterstate highways as an explanatory variable, which was also nonsignificant. 
Mountain regions than in other regions. Equality of the ENC and MOUNTAIN coefficients is rejected, indicating that JITCUS $=1$ is more likely in the East North Central region than in the Mountain region. The predicted probability of JITUSE is 55 percent for an East North Central establishment and 52 percent for a Mountain establishment versus 48 percent for a Pacific region establishment, when other variables are set at their mean values. The JITCUS equation for nonmetro establishments also shows positive effects for the East North Central and Mountain regions (although smaller in magnitude), but there are no significant regional effects for the nonmetro-only JITUSE equation.

The hypothesis that all proximity-related variables (NONMET, $\log$ (ESTABS), INTMI, and regional dummies) are jointly equal to zero is rejected for the full model. The chi-square statistic of 42.6 exceeds the critical value of 26.3 at the $5 \%$ level with 16 degrees of freedom. The hypothesis that the coefficients on $\log$ (ESTABS), INTMI, and regional dummies are jointly equal to zero for the nonmetro model is also rejected. The chi-square statistic is 38.6 with 14 degrees of freedom, which exceeds the critical value of 23.7 at the $5 \%$ level. The rejection is due to the significant regional effects. The hypothesis that the coefficients on NONMET, $\log$ (ESTABS), and INTMI are jointly equal to zero cannot be rejected. While regional effects are significant, other measures of geographic proximity do not appear to contribute significantly to the explanatory power of the model.

Plant characteristics and industry effects appear to be more important than geographic location in explaining JIT use. Branch plants are more likely to use JIT than single-unit plants, but headquarters establishments are not. The nonsignificance of HQ suggests that branch plants are also more likely to use JIT than headquarters plants. The model predicts a probability of using JIT of 54 percent for a branch plant, compared with 48 percent for a single-unit or headquarters plant, evaluated at the means. However, branch and headquarters plants are less likely than single-unit firms to supply a JIT customer, holding other factors constant. The model predicts a probability of supplying a JIT customer of 54 percent for a single-unit plant, compared with 44 percent for a branch plant and 41 percent for a headquarters plant. Effects of branch and headquarters plant status are similar, but of smaller magnitude, for the nonmetro-only model.

The coefficients on $\log (\mathrm{EMP})$ indicate that JIT involvement is positively associated with establishment size. The predicted probability of JITUSE $=1$ rises from 43 percent for an establishment with 10 employees to 52 percent at 100 employees and 58 percent at 500 employees. The establishment size effect for JITCUS is similar to that for JITUSE. The predicted probability that JITCUS $=1$ rises from 43 percent at 10 employees to 54 percent at 100 employees to 61 percent at 500 employees.

Education of the workforce appears to have a modest effect on the likelihood of using JIT. The predicted probability that JITUSE $=1$ rises from 48 percent when half of production workers are high school graduates to 51 percent when all production workers are high school graduates. The education effect is not 
significantly different from zero in the nonmetro model. ${ }^{10}$ New plants are much more likely to be involved in JIT. Newly established (within the previous five years) plants have a predicted probability of JIT use of 61 percent, compared with 49 percent for older establishments, holding other characteristics constant. The effect of NEW is slightly smaller for JITCUS. For nonmetro plants, NEW has a positive effect on JITUSE, but has no significant effect on JITCUS.

The presence of a research and development unit in an establishment has no significant effect on use of JIT, but it has a negative effect on JITCUS in the full model. For the nonmetro model there is no significant effect of RND on JITUSE or JITCUS. Use of outside marketing assistance is associated with an increase from 48 percent to 53 percent in the likelihood of having a JIT customer. Unionization is associated with a 3 percentage point decline in probability of JIT use, but has no effect on the probability of supplying a JIT establishment. Among nonmetro plants, the negative union effect is found for both JITUSE and JITCUS. Large batch production methods do not have any association with JIT involvement.

Industry dummy variable coefficients are shown in an appendix table. In the JITUSE equation, textiles and chemicals had significant negative coefficients, indicating a lower probability of JIT use compared with food processing. Printing, rubber and plastics, and miscellaneous manufacturing had positive coefficients. Predicted probabilities of JITUSE $=1$ (with other variables set at mean values) range from 62 percent for printing to 33 percent for leather products. In the JITCUS equation, the paper, rubber and plastics, fabricated metal products, industrial machinery, and electrical equipment industries have positive coefficients, while apparel, furniture, and miscellaneous manufacturing have negative coefficients. Predicted probabilities for JITCUS $=1$ range from 64 percent for rubber and plastics and 62 percent for paper to 31 percent for the apparel industry.

\section{CONCLUSION}

Manufacturers in relatively isolated rural locations are not precluded from adopting JIT or selling to other firms that use JIT. Nearly half of manufacturing plants in both rural and urban areas report using a JIT system, and a similar percentage report having a customer that uses JIT. Multivariate analysis indicates that proximity to other firms is not a major factor in explaining JIT involvement. If proximity is important to JIT involvement, it is probably at a broader multistate regional level, such as the clustering of new automotive manufacturers across several midwestern and southern states observed by Klier (1995). Mair, Florida, and Kenney (1988) reached a similar conclusion in their study of Japanese automotive transplants in the United States.

Based on the results of this study, JIT does not appear to be a major agglomerative force, and thus does not pose a threat to the rural economy. As other authors have suggested, the well-developed U.S. road system and information technology permit JIT shipments to occur over great distances. Case studies have ${ }^{10}$ Gale (1998) found a similar effect of education on use of manufacturing technology. Local schooling had a positive effect on technology use, but the effect was nonsignificant when the model was estimated for nonmetro establishments only. 
noted that JIT has been adopted by U.S. firms that use suppliers in East Asia. Other factors associated with rural locations (less union power, less historic workermanagement antagonism) may encourage JIT use in rural plants by promoting new "flexible manufacturing" practices that are often associated with JIT. Lower land and labor costs at rural "greenfield" sites may encourage new JIT-using plants to locate in rural areas. These advantages may offset the disadvantage of more isolated rural locations. This study is also consistent with other studies that have found that rural location is not a barrier to the diffusion of innovations.

The multivariate models estimated in this study have low explanatory power. This suggests that adoption of JIT is largely determined by characteristics not included in the models. JIT-adopters cannot easily be classified based on firm characteristics or location. While JIT is often associated with certain industries (transportation, electronics, metalworking, industrial machinery) and production techniques (small batch), this study finds that JIT is widespread across all industries. JIT is used by establishments that produce in both small and large batches. This is consistent with Germain and Dröge (1998), who also found little difference in external characteristics between JIT and non-JIT firms. Germain and Dröge (1998) concluded that "...JIT buying is appropriate across a wide spectrum of operating contexts" (p.18). Future research on JIT adoption will need to take a different approach by perhaps looking at characteristics of managers and their information networks. This study had only a "yes-no" measure of JIT use at a particular point in time. Data that measure the extent of JIT use and follow establishments over a period of time are needed to attain a better understanding of JIT adoption, implementation, and its benefits.

\section{APPENDIX}

APPENDIX TABLE

Industry Dummy Probit Coefficients

\begin{tabular}{lcccccccc}
\hline & \multicolumn{3}{c}{ All observations } & \multicolumn{4}{c}{ Nonmetro only } \\
& \multicolumn{2}{c}{ JITUSE } & \multicolumn{2}{c}{ JITCUS } & \multicolumn{2}{c}{ JITUSE } & JITCUS \\
\hline Food and Kindred Textiles & $-0.34+$ & $(-1.71)$ & -0.07 & $(-0.37)$ & -0.03 & $(-0.18)$ & -0.13 & $(-0.79)$ \\
Apparel & -0.03 & $(-0.19)$ & $-0.67^{*}$ & $(-3.63)$ & 0.19 & $(1.30)$ & -0.22 & $(-1.51)$ \\
Lumber and Wood & -0.02 & $(-0.16)$ & -0.17 & $(-1.43)$ & $-0.19+(-1.83)$ & -0.17 & $(-1.61)$ \\
Furniture & 0.23 & $(1.33)$ & $-0.77^{*}$ & $(-4.02)$ & -0.04 & $(-0.24)$ & $-0.52^{*}(-2.81)$ \\
Paper & -0.16 & $(-1.10)$ & $0.63^{*}$ & $(4.02)$ & $0.31+(1.88)$ & $0.47^{*}$ & $(2.80)$ \\
Printing & $0.65^{*}$ & $(5.55)$ & 0.07 & $(0.60)$ & 0.11 & $(0.70)$ & -0.03 & $(0.18)$ \\
Chemicals & $-0.27^{*}$ & $(-2.03)$ & -0.13 & $(-0.97)$ & $-0.33^{*}(-2.05)$ & -0.21 & $(-1.29)$ \\
Petroleum and Coal & 0.04 & $(0.15)$ & 0.41 & $(1.28)$ & -0.18 & $(-0.64)$ & -0.17 & $(-0.62)$ \\
Rubber and Plastics & $0.28^{*}$ & $(2.34)$ & $0.71^{*}$ & $(5.77)$ & 0.07 & $(0.53)$ & $0.37^{*}$ & $(2.77)$ \\
Leather & -0.60 & $(-0.99)$ & 0.39 & $(0.74)$ & -0.42 & $(-1.13)$ & 0.23 & $(0.71)$ \\
Stone, Clay, Glass & -0.08 & $(-0.61)$ & -0.09 & $(-0.62)$ & $-0.23+(-1.82)$ & $-0.30^{*}(-2.37)$ \\
Primary Metals & -0.12 & $(-0.81)$ & 0.06 & $(0.40)$ & 0.09 & $(0.60)$ & $0.52^{*}$ & $(3.26)$ \\
Fabricated Metal & -0.09 & $(-0.83)$ & $0.31^{*}$ & $(2.97)$ & 0.06 & $(0.52)$ & $0.22+(1.89)$ \\
Industrial Machinery & -0.0004 & $(0.00)$ & $0.18+$ & $(1.83)$ & -0.09 & $(-0.77)$ & 0.04 & $(0.33)$ \\
Electrical Equipment & 0.04 & $(0.34)$ & $0.27^{*}$ & $(2.32)$ & -0.001 & $(-0.01)$ & $0.32^{*}(2.22)$ \\
Transportation Equipment & 0.16 & $(1.22)$ & -0.01 & $(-0.10)$ & $-0.29^{*}$ & $(2.80)$ & -0.01 & $(-0.09)$ \\
Instruments & -0.08 & $(-0.61)$ & 0.10 & $(0.75)$ & 0.21 & $(-1.18)$ & -0.06 & $(-0.28)$ \\
Miscellaneous Manufacturing & $0.32^{*}$ & $(2.48)$ & $-0.36^{*}$ & $(-2.73)$ & 0.31 & $(1.26)$ & -0.21 & $(-1.24)$ \\
\hline
\end{tabular}

Probit coefficients corresponding to models shown in Table 4.

* Significantly different from zero at the $5 \%$ level.

+ Significant at the $10 \%$ level. 


\section{REFERENCES}

Appold, S.J. "Agglomeration, Interorganizational Networks, and Competitive Performance in the U.S. Metalworking Sector." Economic Geography 72 (1995), 27-54.

Barkley, D.L., and M.S. Henry. "Rural Industrial Development: To Cluster or Not to Cluster?" Review of Agricultural Economics 19 (1997), 308-325.

Bernat, A.B. "Manufacturing Restructuring and Rural Economies: Job Growth but Lagging Wages." Rural Development Perspectives 9 (1994), 2-8.

Butler, M.A. Rural-Urban Continuum Codes for Metro and Nonmetro Counties, 1993. USDA-ERS Staff Report AGES 9425. Washington, D.C., Sept. 1994.

Gale, H.F. Is There a Rural-Urban Technology Gap? U.S. Department of Agriculture, AIB-736-01. Washington, D.C., August 1997.

. "Rural Manufacturing on the Crest of the Wave: A Count Data Analysis of Technology Use." American Journal of Agricultural Economics 80 (1998), 347-359.

Gale, H.F., D.A. McGranahan, R. Teixeira, and E. Greenberg. Rural Competitiveness: Results of the 1996 Rural Manufacturing Survey. U.S. Department of Agriculture, Economic Research Service, AER 776. Washington, D.C., March 1999. Germain, R., and C. Dröge. "The Context, Organizational Design, and Performance of JIT Buying Versus Non-JIT Buying Firms." International Journal of Purchasing and Materials Management 34 (1998), 12-18.

Glaeser, E.L., H.D. Kallal, J.A. Scheinkman, and A. Shleifer. "Growth in Cities." Journal of Political Economy 100 (1992), 1126-1152.

Glasmeier, A.K., and R.E. McCluskey. "U.S. Auto Parts Production: An Analysis of a Changing Industry." Economic Geography 63 (1987), 142-159.

Greene, W.H. Limdep, version 7. Bellport, N.Y.: William Greene, Econometric Software, Inc., 1995.

Harrison, B., M.R. Kelley, and J. Gant. "Innovative Firm Behavior and Local Milieu: Exploring the Intersection of Agglomeration, Firm Effects, and Technological Change." Economic Geography 72 (1996), 233-258.

Klier, T. "The Geography of Lean Manufacturing: Recent Evidence From the U.S. Auto Industry." Economic Perspectives (November/December 1995), 2-17.

Kusmin, L.D. "Wage Premiums for On-the-Job Computer use in Metro and Nonmetro Areas." Regional Science Association International, 43rd North American Meeting, Arlington, VA, November 1996.

Linge, G.J.R. "Just-in-Time: More or Less Flexible?” Economic Geography 64 (1991), 316-332.

Little, J.S., and R.K. Triest. "Technology Diffusion in U.S. Manufacturing: The Geographic Dimension." Federal Reserve Bank of Boston Technology and Growth Conference Proceedings. Conference Series No. 40, June 1996.

Livingston, S.G., and E.A. Eff. "Internationalizing the Rural Southeast: The Determinants of Rural Southeastern Manufacturers' Decision to Export." Southern Regional Science Association Annual Meeting, Richmond, VA, April 1999. 
McCann, P., and B. Fingleton. "The Regional Agglomeration Impact of Just-inTime Input Linkages: Evidence From the Scottish Electronics Industry." Scottish Journal of Political Economy 43 (1996), 493-518.

Mair, A., R. Florida, and M. Kenney. "The Geography of Automobile Production: Japanese Transplants in North America." Economic Geography 64 (1988), 352-373.

Moomaw, R.L. "Spatial Productivity Variations in Manufacturing: A Critical Survey of Cross-Sectional Analyses." International Regional Science Review 8 (1983), 1-22.

Nassimbeni, Guido. "Factors Underlying Operational JIT Purchasing Practices: Results of an Empirical Research." International Journal of Production Economics 42 (1995), 275-288.

Rees, J., R. Briggs, and R. Oakey. "The Adoption of New Technology in the American Machinery Industry." Regional Studies 18 (1984), 489-504.

Reid, N. "Just-in-Time Inventory Control and the Economic Integration of Japanese-Owned Manufacturing Plants with the County, State, and National Economies of the United States." Regional Studies 29 (1995), 345-355.

Smith, D.F., and R. Florida. "Agglomeration and Industrial Location: An Econometric Analysis of Japanese-Affiliated Manufacturing Establishments in Automotive-Related Industries." Journal of Urban Economics 36 (1994), 23-41.

Testa, W.A. "Trends and Prospects for Rural Manufacturing." Economic Perspectives (March/April 1993), 27-36.

Wojan, T.R. "Spatial Diffusion of Management Practices in Urban and Rural Areas." Growth and Change 29 (Summer 1998), 319-343. 